\title{
Clinical Focus
}

\section{Are Fenestrated Tracheostomy Tubes Still Valuable?}

\author{
Vinciya Pandian, ${ }^{\text {a }}$ Sarah E. Boisen, ${ }^{\text {b }}$ Shifali Mathews, ${ }^{a}$ and Therese Cole ${ }^{b}$
}

\begin{abstract}
Purpose: The purpose of this clinical focus article is to describe the frequency, indications, and outcomes of fenestrated tracheostomy tube use in a large academic institution.

Method: A retrospective chart review was conducted to evaluate the use of fenestrated tracheostomy tubes between 2007 and 2017. Patients were included in the study if they were $\geq 18$ years of age and received a fenestrated tracheostomy tube in the recent 10 -year period.

Results: Of 2,000 patients who received a tracheostomy, 15 patients had a fenestrated tracheostomy tube; however, only 5 patients received a fenestrated tracheostomy tube at the study institution.

The primary reason why the 15 patients received a tracheostomy was chronic respiratory failure (73\%); other reasons included airway obstruction (20\%) and airway
\end{abstract}

protection (7\%). Thirteen (87\%) patients received a fenestrated tracheostomy tube for phonation purposes. The remaining 2 patients received it as a step to weaning. Of the 13 patients who received a fenestrated tracheostomy tube for phonation, only 1 patient was not able to phonate. Nine (60\%) patients developed some type of complications: granulation only, 2 (13.3\%); granulation and tracheomalacia, 2 (13.3\%); granulation and stenosis, 4 (26.7\%); and granulation, tracheomalacia, and stenosis, 1 (6.7\%).

Conclusions: Fenestrated tracheostomy tubes may assist with phonation in patients who cannot tolerate a 1-way speaking valve; however, the risk of developing granulation tissue, tracheomalacia, and tracheal stenosis exists. Health care providers should be educated on the safe use of a fenestrated tracheostomy tube and other options available to improve phonation while ensuring patient safety.
$\mathrm{T}$ he incidence of tracheostomy in critically ill patients has rapidly grown, so too have efforts to improve the quality of life $(\mathrm{QoL})$ in this patient population (Cipriano et al., 2015; Cox, Carson, Holmes, Howard, \& Carey, 2004). Tracheostomy procedures are often performed as a means to relieve upper airway obstructions, reduce the work of breathing, secure airway protection, and ease the removal of airway secretions (Hess \& Altobelli, 2014). A tracheostomy can also offer additional benefits, such as the ability to facilitate speech (Adam, Srinet, Aronberg, Rosenberg, \& Leder, 2015).

Establishing phonation can often improve QoL for patients with a tracheostomy as well and can be facilitated with the assistance of a variety of devices (Freeman-Sanderson, Togher, Elkins, \& Kenny, 2018; Freeman-Sanderson, Togher, Elkins, \& Phipps, 2016a,

\footnotetext{
${ }^{\mathrm{a} J o h n s ~ H o p k i n s ~ S c h o o l ~ o f ~ N u r s i n g, ~ B a l t i m o r e, ~ M D ~}$

${ }^{\mathrm{b}}$ The Johns Hopkins Hospital, Baltimore, MD

Correspondence to Vinciya Pandian: vpandia1@jhu.edu

Editor-in-Chief: Julie Barkmeier-Kraemer

Editor: Nancy Solomon
}

Received August 27, 2018

Revision received January 31, 2019

Accepted March 29, 2019

https://doi.org/10.1044/2019_AJSLP-18-0187 2016b; Nakarada-Kordic, Patterson, Wrapson, \& Reay, 2018; Ward, Pandian, \& Brenner, 2018). Although speaking valves are most commonly used to achieve phonation with the tracheostomy tube in place, an alternative type of tube known as a fenestrated tracheostomy tube can also be used to help facilitate speech and has proven valuable in certain situations (Hess \& Altobelli, 2014). This special tube has a fenestration or opening of its outer curvature that allows air to pass through the tube and therefore does not necessitate cuff deflation. Cuff deflation is not always clinically feasible in patients who are being mechanically ventilated (Husain, Gatward, \& Harris, 2011; Kluin, Maynard, \& Bogdasarian, 1984; Leder, 1990; Manzano et al., 1993; McGrath, Lynch, Wilson, Nicholson, \& Wallace, 2016; Nomori, 2004; Pandian et al., 2014). As a result, fenestrated tracheostomy tubes have been used to successfully wean patients from the ventilator, serve as a step to weaning, and facilitate phonation; however, their use has been debated among clinicians due to various disadvantages, primarily related to complications such as granulation tissue formation around the site of fenestration (Beard \& Monaco, 1993; Christopher, 2005; Hussey \& Bishop, 1996; Pryor, Ward, Cornwell, O'Connor, \& Chapman, 2016; see Figure 1). 
Figure 1. Benefits, disadvantages, and challenges of using a fenestrated tracheostomy tube. BiPAP = bilevel positive air pressure.

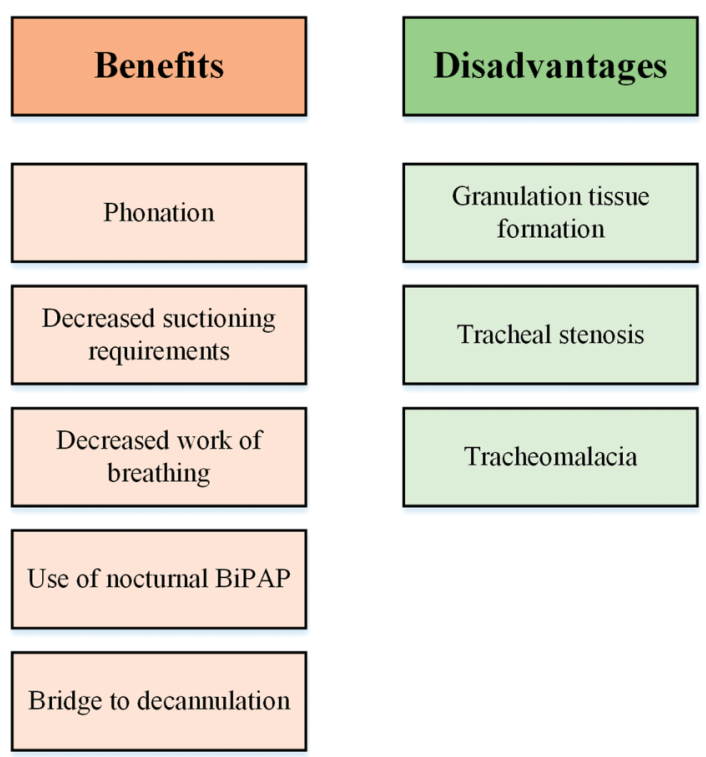

One of the challenges fenestrated tracheostomy tubes present in the clinical setting is that clinicians lack standardized guidelines to help inform patient selection criteria. As a result, there is not a clear consensus related to the timing of tube placement and proper fit with the fenestration. To remedy this, some clinicians have chosen to manually customize the fenestration in standard tracheostomy tubes to improve fit in patients with a unique anatomy (Andersson, 1993; Merritt, Bent, \& Smith, 1997; Snyder, 1983). Because there are no manufacturer's guidelines on how to customize fenestrations, manually creating a fenestration can result in irregular edges that can pose an inherent risk to the patient. Further study of fenestrated tracheostomy tubes is required to assess the complication rates and the perceived benefits encountered by patients utilizing these devices in a clinical setting.

To add to the existing knowledge, we present our experience with fenestrated tracheostomy tubes over a recent 10 -year period. The main purpose of this clinical focus article is to describe the frequency, indications, and outcomes of fenestrated tracheostomy tube use in one large institution. A secondary objective was to compare the patient characteristics, airway-related data, and clinical outcomes between those who received a tracheostomy at the study institution and those who received a tracheostomy outside the study institution to understand why and how the fenestrated tracheostomy tubes were used for patients and what the outcomes were. By describing the diverse settings, indications, and outcomes, each case summary lends a unique perspective that can shed light on the patients' experience of utilizing a fenestrated tracheostomy tube to facilitation phonation, wean from mechanical ventilation, and serve as a step to weaning.

\section{Method}

\section{Theoretical Framework}

Abraham Maslow described that human beings typically prefer lower level needs to be met before those in the higher levels depicted in Figure 2 (Maslow, 1943). Physiological needs are the most basic needs that are required to be fulfilled. For patients with an artificial airway, the ability to speak may be considered just as important as the need to breathe, eat food, drink water, have sex, or sleep. Ability

Figure 2. Schematic of Maslow's hierarchy with examples of speechrelated needs (Maslow, 1943).

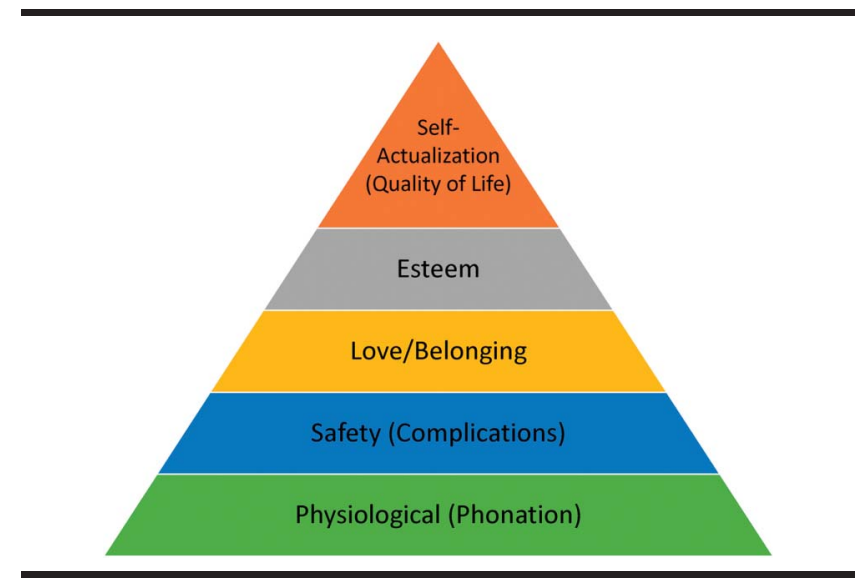


to speak promotes safety as the patients would be able to communicate if they are about to fall or they are not feeling well. Safety while having a fenestrated tracheostomy tube in situ is also a significant concern because of the number of complications such as granulation, tracheomalacia, and tracheal stenosis (see Figure 3). Communication enhances the relationship with health care professionals and family members, thus increasing a sense of love/ belonging or feeling cared for. The needs met at the physiological, safety, and love/belonging levels can promote recognition, help seek attention, maintain social status, help patients feel accomplished, and gain self-respect by having the ability to say yes or no to specific treatment options.

Verbal communication has been found to be far superior to other modes of communication to meet selfesteem needs and, ultimately, self-actualization needs such as meaning to the conversation, sharing of wisdom, obtaining justice, and sharing truths (Freeman-Sanderson et al., 2018). A patient's perception of QoL is related to the progressive satisfaction of a hierarchy of needs (Sirgy, 1986). Meeting the patient's need to communicate and the need to ensure safety with the communication

Figure 3. Cross-sectional drawings of the trachea with poorly positioned fenestrated tracheostomy tubes with inflated cuffs. (Left) Complete obstruction of fenestration by the anterior wall of the trachea. (Right) Partial obstruction of the fenestration by the posterior wall of the trachea. Illustrations printed with permission from the Department of Art as Applied to Medicine, The Johns Hopkins University School of Medicine.

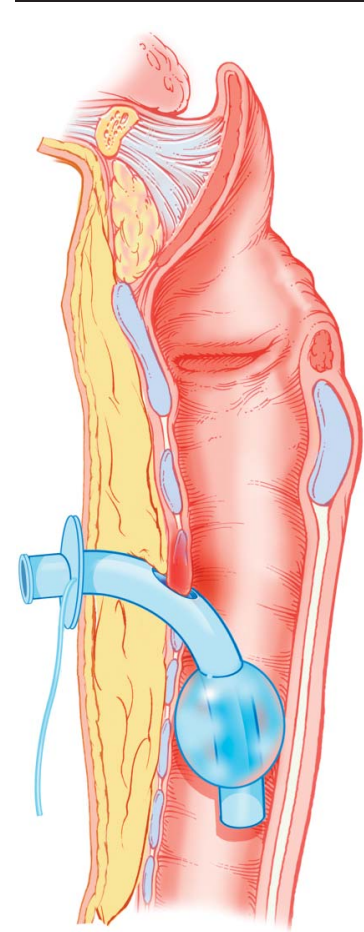

Complete Obstruction

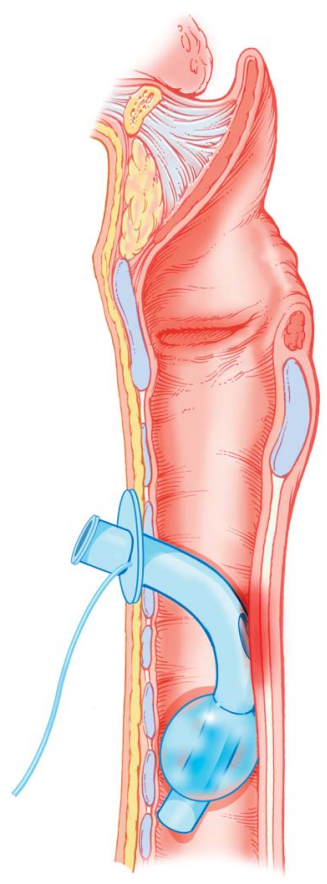

Partial Obstruction

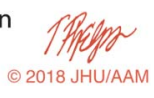

devices is crucial for improving the QoL for patients with a tracheostomy tube for long-term use. The value of fenestrated tracheostomy tubes is operationally defined as the balancing efforts to achieving phonation, a physiological need, or weaning from tracheostomy while promoting safety with the use of fenestrated tracheostomy tubes.

\section{Ethical Consideration}

The study was reviewed by the Johns Hopkins School of Medicine Institutional Review Board and deemed as exempt research under the Department of Health and Human Services regulations (IRB00131121).

\section{Design}

A retrospective chart review was conducted to evaluate the use of fenestrated tracheostomy tubes from April 2007 to April 2017 at a large academic medical center.

\section{Subjects}

Patients were included in the study if they were 18 years of age or older and had a fenestrated tracheostomy tube at the study institution.

\section{Data Collection}

Patient characteristics including patient's age, sex, primary admitting diagnosis, and location where the patient received the initial tracheostomy were collected (within study institution vs. outside hospital). Airwayrelated data included duration of intubation prior to receiving a tracheostomy, reason for a tracheostomy, initial tracheostomy type and size, fenestrated tracheostomy tube and size, reason for fenestrated tracheostomy tube, intended duration of fenestrated tube, and actual duration of any type of tracheostomy from the time the patients received a tracheostomy until they were discharged from our institution. We also collected data on clinical outcomes such as the ability to phonate, the ability to swallow, the presence of granulation, tracheomalacia, tracheal stenosis, hospital length of stay, and whether the patient still had a tracheostomy at the time of discharge from our hospital. Data were collected by two research assistants (S. B. and S. M.), and data were validated by a speech-language pathologist (SLP; T. C.) and a nurse practitioner (V. P.).

\section{Statistical Analysis}

In addition to describing each of the cases for whom a fenestrated tracheostomy tube was placed in the study hospital, we also compared patient characteristics and clinical outcomes between those who received a fenestrated tracheostomy tube within the hospital and those who received a fenestrated tracheostomy tube outside the hospital to evaluate for any variation in practices (see Table 1). Means, standard deviations, frequencies, and percentages were calculated for descriptive purposes. Student's $t$ test was used to compare parametric data, 
Table 1. Comparison of data between patients who received a fenestrated tracheostomy within the study hospital versus those who received a fenestrated tracheostomy outside the study hospital.

\begin{tabular}{|c|c|c|c|c|}
\hline Patient characteristics & & Study hospital $(n=5)$ & Outside hospital $(n=10)$ & $p$ \\
\hline \multicolumn{2}{|l|}{ Age } & $44.2 \pm 16.5$ & $54.8 \pm 14.2$ & .21 \\
\hline Sex & Women & $5(100)$ & $4(40)$ & .02 \\
\hline \multirow[t]{3}{*}{ Admitting diagnosis } & Cardiac & $1(20)$ & $1(10)$ & \multirow{3}{*}{.56} \\
\hline & Neurological & $3(60)$ & $4(40)$ & \\
\hline & Cancer & 0 & $3(30)$ & \\
\hline \multicolumn{2}{|l|}{ Length of intubation } & $\begin{array}{l}10.2 \pm 4.9 \\
\quad(n=5)\end{array}$ & $\begin{array}{l}12 \pm 9.7 \\
(n=4)^{\mathrm{a}}\end{array}$ & .72 \\
\hline \multirow{3}{*}{ Reason for a tracheostomy } & Airway obstruction & 0 & $3(30)$ & \multirow[t]{3}{*}{.17} \\
\hline & Chronic respiratory failure & $4(80)$ & $7(70)$ & \\
\hline & Airway protection & $1(20)$ & 0 & \\
\hline $\begin{array}{l}\text { Type of tracheostomy tube initially } \\
\text { inserted }\end{array}$ & Cuffed 6.0 & $5(100)$ & $2(20)$ & .01 \\
\hline \multirow{2}{*}{$\begin{array}{l}\text { Type of fenestrated tracheostomy } \\
\text { tube the patient initially received }\end{array}$} & Cuffless 6.0 & $1(20)$ & $2(20)$ & \multirow{2}{*}{.55} \\
\hline & Cuffless 8.0 & 0 & $1(10)$ & \\
\hline \multirow{3}{*}{$\begin{array}{l}\text { Reason for fenestrated tracheostomy } \\
\text { tube }\end{array}$} & Phonation & $3(60)$ & 10 (100) & \multirow[t]{3}{*}{.09} \\
\hline & Capping trial & $1(20)$ & 0 & \\
\hline & Transition to BiPAP & $1(20)$ & 0 & \\
\hline \multirow{3}{*}{$\begin{array}{l}\text { The duration fenestrated tube was } \\
\text { intended for }\end{array}$} & Short term $<2$ months & $2(40)$ & 0 & \multirow[t]{2}{*}{.03} \\
\hline & Long term: 2 months or greater & $3(60)$ & $10(100)$ & \\
\hline & \multicolumn{4}{|c|}{ Clinical outcomes } \\
\hline Ability to phonate & & $4(80)$ & $9(90)$ & .59 \\
\hline Ability to swallow & & $2(40)$ & $4(40)$ & 1.0 \\
\hline \multirow[t]{3}{*}{ Complications } & Granulation tissue & $2(40)$ & $7(70)$ & .26 \\
\hline & Tracheomalacia & $1(20)$ & $2(20)$ & 1.0 \\
\hline & Stenosis & $1(20)$ & $4(40)$ & .44 \\
\hline Hospital lengths of stay & & $76.2 \pm 44.2$ & $119.3 \pm 105.2$ & .54 \\
\hline
\end{tabular}

Note. BiPAP = bilevel positive air pressure.

${ }^{a}$ Data unknown for the remaining patients.

and Wilcoxon's rank-sum test was used to compare nonparametric data. Chi-square test was used to compare categorical variables.

\section{Results}

About 2,000 patients received a tracheostomy at our institution in the inpatient settings: an average of 180-200 patients per year. Of these 2,000 patients, 15 patients had a fenestrated tracheostomy tube over a 10 -year period. However, only five of these patients received a fenestrated tracheostomy tube at our institution. The remaining 10 patients received a fenestrated tracheostomy tube at an outside institution before getting admitted to our institution. Indications, benefits, and challenges associated with the use of a fenestrated tracheostomy tube for patients who received a fenestrated tracheostomy tube within our institution are described below.

\section{Description of All Patients With a Fenestrated Tracheostomy Tube}

The mean age of all 15 patients who received a fenestrated tracheostomy tube was $51 \pm 15$ years; $60 \%$ of them were women. The primary admitting diagnosis was neurological $(47 \%)$. The actual admitting diagnosis is provided in Table 2. The mean duration of intubation for nine patients for whom we were able to retrieve data was $9 \pm 6$ days. The primary reason why these patients received a tracheostomy was chronic respiratory failure (73\%; see Table 3$)$. Thirteen $(87 \%)$ patients received a fenestrated tracheostomy tube for phonation purposes. The remaining two received it as a step to weaning. Of the 13 patients who received a fenestrated tracheostomy tube for phonation, only one patient was not able to phonate (see Table 4). Six (40\%) patients passed the videofluoroscopy swallow study and were able to eat; the remaining nine patients had a percutaneous endoscopic gastrostomy tube for feeding and did not return to oral 
Table 2. Patient characteristics.

\begin{tabular}{|c|c|c|c|c|c|c|}
\hline Patient ID & $\begin{array}{c}\text { Age } \\
\text { (years) }\end{array}$ & $\begin{array}{l}\text { Age } \\
\text { category }\end{array}$ & Sex & Admitting diagnosis & Diagnosis category & $\begin{array}{l}\text { Location where the patient } \\
\text { received initial tracheostomy }\end{array}$ \\
\hline A & 63 & $\begin{array}{l}>60 \\
\text { Older adult }\end{array}$ & Female & Restrictive lung disease & Pulmonary & Study hospital \\
\hline B & 31 & $\begin{array}{l}18-35 \\
\text { Young adult }\end{array}$ & Female & Spinocerebellar ataxia type 2 & Neuro & Study hospital \\
\hline C & 29 & $\begin{array}{l}18-35 \\
\text { Young adult }\end{array}$ & Female & Cerebral palsy & Neuro & Study hospital \\
\hline E & 61 & $\begin{array}{l}>60 \\
\text { Older adult }\end{array}$ & Female & Spinocerebellar ataxia type 2 & Neuro & Study hospital \\
\hline $\mathrm{F}$ & 57 & $\begin{array}{l}\text { 35-60 } \\
\text { Middle-aged adult }\end{array}$ & Female & $\begin{array}{l}\text { Scleroderma and pulmonary } \\
\text { hypertension }\end{array}$ & Pulmonary & Outside hospital \\
\hline G & 35 & $\begin{array}{l}18-35 \\
\text { Young adult }\end{array}$ & Female & Relapsing polychondritis & Neuro & Outside hospital \\
\hline K & 60 & $\begin{array}{l}35-60 \\
\text { Middle-aged adult }\end{array}$ & Male & Amyotrophic lateral sclerosis & Neuro & Outside hospital \\
\hline L & 72 & $\begin{array}{l}>60 \\
\text { Older adult }\end{array}$ & Male & $\begin{array}{l}\text { Severe COPD; status post } \\
\text { single lung transplant }\end{array}$ & Pulmonary & Outside hospital \\
\hline M & 33 & $\begin{array}{l}18-35 \\
\text { Young adult }\end{array}$ & Male & $\begin{array}{l}\text { Tracheal stenosis; cerebral } \\
\text { palsy; developmental delay }\end{array}$ & Neuro & Outside hospital \\
\hline $\mathrm{N}$ & 42 & $\begin{array}{l}35-55 \\
\text { Middle-aged adult }\end{array}$ & Female & $\begin{array}{l}\text { End-stage cardiomyopathy; } \\
\text { pulmonary hypertension }\end{array}$ & Cardiac & Outside hospital \\
\hline $\mathrm{O}$ & 66 & $\begin{array}{l}>60 \\
\text { Older adult }\end{array}$ & Male & Non-Hodgkin's lymphoma & Cancer & Outside hospital \\
\hline
\end{tabular}

Note. $\mathrm{s} / \mathrm{p}=$ status post $\mathrm{COPD}=$ chronic obstructive pulmonary disease.

intake while they were admitted in our hospital. Nine $(60 \%)$ patients developed some type of complications: granulation, $9(60 \%)$; tracheomalacia, 3 (20\%); and tracheal stenosis, $5(33 \%)$. The average number of days the patients remained in the hospital was $104.9 \pm 90$. Five patients $(33 \%)$ got decannulated prior to discharge, whereas the remaining 10 patients got discharged with a tracheostomy. Seven out of 10 outside-hospital patients were discharged with a

Table 3. Airway-related data.

\begin{tabular}{|c|c|c|c|c|c|c|c|}
\hline Patient ID & $\begin{array}{l}\text { Duration of } \\
\text { intubation } \\
\text { (days) }\end{array}$ & $\begin{array}{l}\text { Reason for a } \\
\text { tracheostomy }\end{array}$ & $\begin{array}{l}\text { Initial } \\
\text { tracheostomy } \\
\text { type and size }\end{array}$ & $\begin{array}{l}\text { Fenestrated } \\
\text { tube type } \\
\text { and size }\end{array}$ & $\begin{array}{c}\text { Reason for } \\
\text { fenestrated } \\
\text { tube }\end{array}$ & $\begin{array}{c}\text { Intended } \\
\text { duration of } \\
\text { fenestrated tube }\end{array}$ & $\begin{array}{l}\text { Actual duration } \\
\text { of any type of } \\
\text { tracheostomy }\end{array}$ \\
\hline A & 4 & Chronic respiratory failure & Cuffed 6.0 & Cuffed 6.0 & Phonation & Long term & 390 \\
\hline B & 14 & Airway protection & Cuffed 6.0 & Cuffless 6.0 & Phonation & Long term & 31 \\
\hline C & 16 & Chronic respiratory failure & Cuffed 6.0 & Cuffless 4.0 & Capping trial & Short term & 58 \\
\hline $\mathrm{D}$ & 10 & Chronic respiratory failure & Cuffed 6.0 & Cuffless 4.0 & BiPAP & Short term & 124 \\
\hline$E$ & 7 & Chronic respiratory failure & Cuffed 6.0 & Cuffless 4.0 & Phonation & Long term & 92 \\
\hline $\mathrm{F}$ & 22 & Chronic respiratory failure & Cuffed 8.0 & Cuffed 6.0 & Phonation & Long term & Unknown \\
\hline G & Unknown & Airway obstruction & Unknown & Cuffless 6.0 & Phonation & Long term & Unknown \\
\hline $\mathrm{H}$ & 18 & Chronic respiratory failure & Cuffed 6.0 & Cuffless 4.0 & Phonation & Long term & Unknown \\
\hline 1 & 7 & Chronic respiratory failure & Cuffed 6.0 & Cuffed 6.0 & Phonation & Long term & Unknown \\
\hline J & 1 & Airway obstruction & Cuffed 8.0 & Cuffless 8.0 & Phonation & Long term & Unknown \\
\hline K & Unknown & Chronic respiratory failure & Unknown & Cuffed 6.0 & Phonation & Long term & Unknown \\
\hline $\mathrm{L}$ & Unknown & Chronic respiratory failure & Unknown & Cuffed 8.0 & Phonation & Long term & Unknown \\
\hline M & Unknown & Airway obstruction & Unknown & Cuffless 4.0 & Phonation & Long term & Unknown \\
\hline $\mathrm{N}$ & Unknown & Chronic respiratory failure & Unknown & Cuffless 6.0 & Phonation & Long term & Unknown \\
\hline $\mathrm{O}$ & Unknown & Chronic respiratory failure & Unknown & Cuffed 6.0 & Phonation & Long term & Unknown \\
\hline
\end{tabular}

Note. BiPAP = bilevel positive air pressure. 
Table 4. Clinical outcomes.

\begin{tabular}{lcccccc}
\hline Patient ID & $\begin{array}{c}\text { Ability to } \\
\text { phonate }\end{array}$ & $\begin{array}{c}\text { Ability to } \\
\text { swallow }\end{array}$ & $\begin{array}{c}\text { Presence of } \\
\text { granulation }\end{array}$ & Tracheomalacia & $\begin{array}{c}\text { Tracheal } \\
\text { stenosis }\end{array}$ & $\begin{array}{c}\text { Hospital length } \\
\text { of stay }\end{array}$ \\
\hline A & Yes & No & Yes & Yes & No & 24 \\
status
\end{tabular}

fenestrated tube in situ (see Table 4). When clinical outcomes were compared between the three age groups, there was no significant difference.

\section{Description of Patients Who Received a Fenestrated Tracheostomy Tube at the Study Hospital}

Because we were able to obtain data from the time a tracheostomy was surgically created until the patients were discharged from the hospital, we present more detailed information about the clinical course of patients who received a fenestrated tracheostomy tube at the study site.

\section{Patient A}

A 63-year-old, mechanically ventilated patient with chronic respiratory failure secondary to restrictive lung disease received a fenestrated tracheostomy tube to help facilitate phonation. After 21 days, she presented with dysphonia and dyspnea when capping her fenestrated tracheostomy tube. Tracheomalacia and a significant amount of granulation tissue were noted upon bronchoscopy at the level of the tracheostomy stoma. The size 6.0 cuffed fenestrated tube was changed to a size 4.0 cuffed nonfenestrated tube to decrease the growth of granulation tissue in the upper airway. Upon reassessment 2 weeks later, she was found to still have evidence of granulation tissue along with tracheal stenosis and tracheomalacia; therefore, the tracheostomy tube was changed from a size 4.0 backup to a size 6.0. One year later, she was able to wean off of the ventilator successfully; however, the presence of tracheal stenosis impeded successful decannulation. The fenestrated tube helped with phonation, but the complications overweighed the benefits.

\section{Patient B}

A 31-year-old patient with spinocerebellar ataxia type 2 received a tracheostomy for airway protection. She was able to successfully wean from the ventilator the following day to a tracheostomy collar. Although she was able to tolerate the tracheostomy collar on room air, she was unable to phonate successfully with cuff deflation and speaking valve. A decision was made to change her tracheostomy tube to a cuffless fenestrated tracheostomy tube to facilitate phonation and to ultimately improve her QoL. Although the procedure was tolerated without difficulty, overnight, she desaturated to $85 \%$ and was placed on a facemask with $\mathrm{fiO}_{2} 35 \%$ and $\mathrm{SpO}_{2} 92 \%$. The cause was found to be related to new bilateral infiltrates and not related to the tracheostomy tube change; therefore, she continued utilizing a fenestrated cuffless tracheostomy tube. She was eventually discharged with a fenestrated tube in place 1 month later once her underlying medical condition was stabilized. We were unable to conduct follow-up as she traveled out of state to live with family. The benefit of phonation was not affected by any complications associated with a fenestrated tracheostomy tube.

\section{Patient C}

A 29-year-old patient with cerebral palsy received a tracheostomy for chronic ventilator dependence status post pneumonia. The patient was eventually weaned off the ventilator and ready for decannulation; however, given the patient's small airway diameter, she was not appropriate for the capping trial even with a 4.0 cuffless nonfenestrated Shiley tracheostomy tube. To facilitate a safe capping trial, the patient's tracheostomy tube was changed to a 4.0 cuffless fenestrated Shiley tracheostomy tube. After the tube change, a decrease in air trappings was reported and she was able to tolerate the one-way speaking valve for $5 \mathrm{~min}$. One week later, there was continued concern for adequate air passage around the tracheostomy tube as she was unable to vocalize during the speech therapy session. The patient remained inappropriate for plugging trials and was switched back to a 6.0 cuffed Portex tube, which had a smaller outer diameter than the size 4.0 Shiley tube, with similar challenges with trials of a one-way speaking valve. A decision was made to not decannulate, and she was discharged to home with a tracheostomy tube. The benefits of being able to wean the patient from the tracheostomy tube added value temporarily. 


\section{Patient D}

A 37-year-old patient received a tracheostomy due to prolonged respiratory failure resulting from postoperative diaphragmatic paralysis status post heart and bilateral lung transplant secondary to interstitial lung disease, pulmonary hypertension, and cardiomyopathy. After being on the ventilator for several months, she was transitioned from a size 6.0 nonfenestrated Shiley to a fenestrated Shiley tube for a nocturnal facial mask bilevel positive airway pressure (BiPAP). She was then able to tolerate the nocturnal BiPAP via nasal mask with fenestrated tracheostomy tube capped, tolerate the room air during the day, and ambulate without any shortness of breath or difficulty, which made her feel stable for discharge to home. The tracheostomy tube was eventually capped for $24 \mathrm{hr}$ and then decannulated. The ability to wean the patient from her tracheostomy safely was of value.

\section{Patient E}

A 61-year-old patient with respiratory and heart failure and spinocerebellar ataxia type 2 received a tracheostomy for airway protection during cardiac surgery and chronic hypoxia. She had intermittent, significantly strained vocal quality and aphonic quality with digital occlusion due to the high placement of the tracheostomy tube. Upon evaluation, she was found to have granulation tissue at the tracheostomy insertion site internally at the level of the vocal folds, which caused glottic stenosis that was treated with steroid injections. She was taught how to perform digital occlusion to phonate with one-word utterances. She also had increased coughing and was able to mobilize blood-tinged secretions. A decision was made to place a fenestrated tracheostomy tube to help with phonation because there was no air movement around the tracheostomy tube. A benefit of the fenestrated tracheostomy tube was a lower suctioning requirement, and she was able to wear the speaking valve for about $50 \mathrm{~min}$ at a time. The granulation tissue was removed surgically, followed by successful capping trial and decannulation. The benefit of phonation while awaiting underlying tissue healing was of significant value for this patient.

\section{Comparison of Data Between Patients Who Received a Fenestrated Tracheostomy Tube at the Study Hospital and Outside Hospital}

Patients who received a fenestrated tube were all women at our institution unlike outside hospitals $(p=.02$; see Table 4). There was no significant difference in the age, admitting diagnosis, or length of intubation prior to receiving a tracheostomy tube. In our institution, patients typically receive a cuffed 6.0 tracheostomy tube as their initial type of tracheostomy tube, whereas variations are noted in patients who received a tracheostomy tube in hospitals outside our institution $(p=.01)$. The primary reason why a patient received a tracheostomy in outside hospitals was only phonation (100\%); patients at our hospital received a tracheostomy as a mode to wean off the tracheostomy tube: phonation, $3(60 \%)$; capping trial, $1(20 \%)$; and transition to BiPAP, $1(20 \% ; p=0)$. Regardless of where they received a tracheostomy, all patients had received a tracheostomy for long-term management, but two patients received a fenestrated tracheostomy tube for short-term indications. No significant differences between the two groups were noted in the clinical outcomes such as complications or hospital lengths or stay. All patients who received a fenestrated tracheostomy tube in our institution had a gastrostomy tube. Notably, nine $(60 \%)$ out of 15 patients developed some form of granulation tissue in the trachea in proximity to the fenestration.

\section{Discussion}

The overall findings of our study suggest that the frequency of the use of a fenestrated tracheostomy tube is rare and often reserved for unique situations. The value of a fenestrated tube included improved ability to phonate with digital occlusion or one-way speaking valves, decreased suctioning requirements, decreased work of breathing, and the ability to tolerate nocturnal BiPAP. The duration of fenestrated tracheostomy tube use among those patients who received a tracheostomy at the study hospital ranged from 31 to 390 days. Patient safety concerns included the formation of granulation tissue, tracheomalacia, and tracheal stenosis.

Whereas the incidence of tracheostomy in critically ill patients has tripled in recent years, the use of fenestrated tracheostomy tubes has not seen similar increases. The increase is primarily due to a wide range of short- and longterm complications and lack of clinical guidance regarding their use, which deter clinicians from recommending a fenestrated tube. Our findings show that, within a 10 -year span at an academic tertiary medical center, 2,000 patients received a tracheostomy, whereas only five patients received a fenestrated tube; of these, only two were able to tolerate its use. Literature reporting the use of fenestrated tracheostomy tubes is minimal.

In our study, 13 out of 15 patients $(86.7 \%)$ received a fenestrated tracheostomy tube for phonation that can be perceived as a very important basic need (Maslow, 1943). Studies that have investigated the use of fenestrated tracheostomy tubes found similar benefits regarding improvements in phonation (de la Cruz, Islam, \& Cloyes, 2013; Pryor et al., 2016). Both patient-based studies in the literature and cases from our hospital have shown that fenestrated tracheostomy tubes aid in increasing voice intensity and do not necessitate cuff deflation in mechanically ventilated patients to facilitate phonation (Adam et al., 2015; Kunduk et al., 2010; Leder et al., 2013).

Regarding complications, granulation tissue presented as a common problem across both the literature (Alvi \& Zahtz, 1994; Carron, Kim, Sawhney, \& Reidy, 2006; Siddharth \& Mazzarella, 1985) and our findings (60\%). Development of granulation tissue is attributed to some of the tracheal mucosa getting sucked into the fenestration 
during tracheal suctioning or the presence of the fenestration at the wrong location as it pertains to the patient's airway anatomy (Carron et al., 2006). The fenestration can be present in the tracheostomy stoma tract or too close to the posterior wall of the trachea, leading to partial or complete obstruction of the fenestration causing impaired voice quality. Besides, malpositioning can irritate the tracheal mucosa, resulting in granulation tissue formation, tracheal stenosis, and tracheomalacia (see Figure 3). Although there were descriptions of granulation tissue, tracheal stenosis, and tracheomalacia in our patients, one cannot rule out tracheal injury from prolonged intubation and a potential etiology for granulation (Brodsky et al., 2018). Some studies have noted that, by manually cutting fenestrations into standard tracheostomy tubes at a location that is best for the patient's anatomy, clinicians can help ensure a better fit with a certain unique anatomy of the patient; however, this was not the practice in reviewing the patients who received a fenestrated tracheostomy tube in our study institution (Andersson, 1993; Snyder, 1983).

In addition to the formation of granulation tissue, studies have reported anxiety, oxygen desaturation, hypotension, chest tightness, and insomnia with the use of fenestrated tracheostomy tubes (Adam et al., 2015; Kunduk et al., 2010; Leder, 1990). We were unable to correlate these signs and symptoms to the use of fenestrated tracheostomy tube because our study was retrospective and limited to information documented in the patient's medical records. Nevertheless, such symptoms have been reported among patients using a nonfenestrated tracheostomy tube as well (Büntzel, 2014).

Among patients who received a tracheostomy within the study institution, the duration of fenestrated tracheostomy tube use ranged from 19 days to 2 months and was primarily indicated not only for long-term use for phonation but also for short-term uses such as a step to weaning, as a transition to nocturnal BiPAP, or for assistance in weaning from the ventilator in our chart review. The literature reports the use of fenestrated tracheostomy tubes for an average of 41149 days (Adam et al., 2015; Kunduk et al., 2010; Leder, 1990). From the interprofession practice records, authors have noted patients coming to the institution's outpatient clinic with a fenestrated tracheostomy tube for several years. Institutions that regularly use fenestrated tracheostomy tubes without complications have not published their data. As a result, existing literature is limited to those that primarily describe the disadvantages, a negative value, of using a fenestrated tracheostomy tube.

Our chart review revealed that utilizing a fenestrated tracheostomy tube in critically ill patients requiring mechanical ventilation is not a common practice. A lack of scientific consensus regarding the timing of tube placement has made patient selection criteria challenging for clinicians who are wary of compromising the safety of their patients. The clinical course of the five patients included who received a tracheostomy at our institution indicates that there remains variation in the indication for the use of a fenestrated tracheostomy tube. The potential development of short- and long-term complications - coupled with unclear guidelines that fail to support the clinician in appropriately pairing the timing of tube placement with the patient's diagnosis - often discounts consideration of their use to support successful outcomes. Therefore, further research is imperative to understand the value a fenestrated tracheostomy tube can provide for critically ill patients.

Addressing patient safety concerns is crucial for the patients to develop trust in health care providers and to improve QoL (Maslow, 1943). Several options for troubleshooting while caring for a patient with a tracheostomy tube may be considered. SLPs and patient care teams who use fenestrated tracheostomy tubes may want to ensure that an inner cannula without fenestration is used to decrease the trauma to the tracheal mucosa (Wiegand \& Carlson, 2010). Clinicians who insert fenestrated tracheostomy tubes or perform regular tracheostomy tube changes may need to ensure that the fenestration is in the correct place (not pressing against the tracheal walls) immediately after placement. When SLPs note a worsening of the quality of phonation, they may want to suspect malpositioning of the tracheostomy tube or the formation of granulation tissue. Experienced SLPs, advanced practice providers, or physicians may consider scoping the tracheostomy tube using a flexible laryngoscope to evaluate the positioning of the fenestration and the potential presence of granulation tissue. If malpositioning is noted, repositioning or replacing the tracheostomy tube may be considered (Berlet \& Marchon, 2016). If granulation tissue is noted to occlude the fenestration, then extreme caution needs to be used while replacing the tracheostomy tube as it can potentially place the patient at a high risk for bleeding into the airway and potential respiratory arrest (Berlet \& Marchon, 2016). Clinicians may consider the use of silver nitrate or a similar product to shrink the granulation tissue before removing the tracheostomy tube if the granulation tissue is visibly grown into the fenestration of the tracheostomy tube (Rehm, Wanek, Gagnon, Pearson, \& Mullins, 2002).

There is another patient safety aspect that patient care teams need to consider: There can be significantly reduced airflow with the fenestrated tracheostomy tube if the cuff is inflated and a speaking valve is used (Berlet \& Marchon, 2016). Reduction in airflow would be of significant concern especially if the patient also has an upper airway pathology that might decrease the diameter of the airway or when using a nonfenestrated inner cannula (Passy-Muir, 2003). Patient care teams should use critical thinking and clinical reasoning when deciding whether to use a speaking valve in a patient with a fenestrated tracheostomy tube with the cuff inflated.

The limitations of our chart review are that it is retrospective in nature and the sample size is small, which limits the ability to generate clinical recommendations and generalizability. Several data-such as how long the patient was intubated or had a tracheostomy and whether the complications occurred after the placement of a tracheostomy tubewere not available for patients who received a tracheostomy tube outside our institution. However, the retrospective 
chart review described provides insight into the value of these tubes and a foundation for future research.

Fenestrated tracheostomy tubes have a number of potential benefits that may improve the clinical outcomes in patients requiring a tracheostomy tube; however, it is fraught with disadvantages as well. To ensure patient safety as the incidence of tracheostomy among critically ill patients continues to increase, it is imperative that patient care teams are adequately educated on the different options available to help support improvements in clinical outcomes and to use strict criteria for patient selection for the use of fenestrated tracheostomy tubes.

\section{Acknowledgments}

This is an investigator-initiated grant funded by Medtronic, awarded to Johns Hopkins School of Nursing. Medtronic had no role in project design or execution. Medtronic approved this submission without any modification to manuscript content. Pandian has received two research grants from the National Institutes of Health (NIH). She is funded through the NIH/National Institute of Nursing Research to assess symptoms and screen for laryngeal injury postextubation in intensive care unit settings (Grant R01NR017433-01A1). She is also funded through NIH/ National Institute of Aging to evaluate the effectiveness of a novel arm restraint for intubated patients with cognitive impairment to reduce agitation, sedation, and immobility (Grant R42AG059451). We thank Martin Blair, Editor, for providing editorial support.

\section{References}

Adam, S. I., Srinet, P., Aronberg, R. M., Rosenberg, G., \& Leder, S. B. (2015). Verbal communication with the Blom low profile and Passy-Muir one-way tracheotomy tube speaking valves. Journal of Communication Disorder, 56, 40-46. https://doi.org/ 10.1016/j.jcomdis.2015.06.003

Alvi, A., \& Zahtz, G. D. (1994). Fracture of a synthetic fenestrated tracheostomy tube: Case report and review of the literature. American Journal of Otolaryngology, 15(1), 63-67. Retrieved from http://www.sciencedirect.com/science/article/ pii/0196070994900434?via\%3Dihub

Andersson, G. (1993). The Swedish modification of the tracheostomy tube to permit speech. Paraplegia, 31(4), 203-206. https://doi. org $/ 10.1038 / \mathrm{sc} .1993 .38$

Beard, B., \& Monaco, F. J. (1993). Tracheostomy discontinuation: Impact of tube selection on resistance during tube occlusion. Respiratory Care, 38(3), 267-270.

Berlet, T., \& Marchon, M. (2016). Leakage characteristics of dual-cannula fenestrated tracheostomy tubes during positive pressure ventilation: A bench study. Anesthesiology Research and Practice, 2016, 9272865. https://doi.org/10.1155/2016/ 9272865

Brodsky, M. B., Levy, M. J., Jedlanek, E., Pandian, V., Blackford, B., Price, C., ... Akst, L. M. (2018). Laryngeal injury and upper airway symptoms after oral endotracheal intubation with mechanical ventilation during critical care: A systematic review. Critical Care Medicine, 46(12), 2010-2017. https://doi.org/10.1097/ CCM.0000000000003368

Büntzel, J. (2014). Palliativmedizin in der HNO-Heilkunde [Palliative care in otolaryngology]. HNO, 62(5), 335-341. https:// doi.org/10.1007/s00106-014-2842-4
Carron, M. A., Kim, S. A., Sawhney, R., \& Reidy, P. (2006). Airway obstruction by granulation tissue within a fenestrated tracheotomy tube: Case report. Ear Nose Throat Journal, 85(1), 54-55.

Christopher, K. L. (2005). Tracheostomy decannulation. Respiratory Care, 50(4), 538-541. Retrieved from http://rc.rcjournal. com/content $/ 50 / 4 / 538$.short

Cipriano, A., Mao, M. L., Hon, H. H., Vazquez, D., Stawicki, S. P., Sharpe, R. P., \& Evans, D. C. (2015). An overview of complications associated with open and percutaneous tracheostomy procedures. International Journal Critical of Illness \& Injury Science, 5(3), 179-188. https://doi.org/10.4103/2229-5151.164994

Cox, C. E., Carson, S. S., Holmes, G. M., Howard, A., \& Carey, T. S. (2004). Increase in tracheostomy for prolonged mechanical ventilation in North Carolina, 1993-2002. Critical Care Medicine, 32(11), 2219-2226.

de la Cruz, M., Islam, S., \& Cloyes, R. (2013). Novel modification of tracheostomy tube to allow speech and manage tracheal stenosis. British Medical Journal Case Report, 2013. http://dx.doi. org/10.1136/bcr-2013-200622

Freeman-Sanderson, A. L., Togher, L., Elkins, M., \& Kenny, B. (2018). Quality of life improves for tracheostomy patients with return of voice: A mixed methods evaluation of the patient experience across the care continuum. Intensive Critical Care Nurse, 46, 10-16. https://doi.org/10.1016/j. iccn.2018.02.004

Freeman-Sanderson, A. L., Togher, L., Elkins, M. R., \& Phipps, P. R. (2016a). Quality of life improves with return of voice in tracheostomy patients in intensive care: An observational study. Journal of Critical Care, 33, 186-191. https://doi.org/ 10.1016/j.jcrc.2016.01.012

Freeman-Sanderson, A. L., Togher, L., Elkins, M. R., \& Phipps, P. R. (2016b). Return of voice for ventilated tracheostomy patients in ICU: A randomized controlled trial of early-targeted intervention. Critical Care Medicine, 44(6), 1075-1081.

Hess, D. R., \& Altobelli, N. P. (2014). Tracheostomy tubes. Respiratory Care, 59(6), 956-973. https://doi.org/10.4187/ respcare.02920. Retrieved from http://rc.rcjournal.com/content/59/6/956. short

Husain, T., Gatward, J. J., \& Harris, R. D. (2011). Use of subglottic suction port to enable verbal communication in ventilatordependent patients. American Journal of Respiratory Critical Care Medicine, 184(3), 384. https://doi.org/10.1164/ajrccm. 184.3.384

Hussey, J. D., \& Bishop, M. J. (1996). Pressures required to move gas through the native airway in the presence of a fenestrated vs a nonfenestrated tracheostomy tube. Chest, 110(2), 494 497. https://doi.org/10.1378/chest.110.2.494

Kluin, K. J., Maynard, F., \& Bogdasarian, R. S. (1984). The patient requiring mechanical ventilatory support: Use of the cuffed tracheostomy "talk" tube to establish phonation. OtolaryngologyHead \& Neck Surgery, 92(6), 625-627. https://doi.org/10.1177/ 019459988409200606

Kunduk, M., Appel, K., Tunc, M., Alanoglu, Z., Alkis, N., Dursun, G., \& Ozgursoy, O. B. (2010). Preliminary report of laryngeal phonation during mechanical ventilation via a new cuffed tracheostomy tube. Respiratory Care, 55(12), 1661-1670. Retrieved from http://rc.rcjournal.com/content/55/12/1661.short

Leder, S. B. (1990). Verbal communication for the ventilatordependent patient: Voice intensity with the Portex "Talk" tracheostomy tube. The Laryngoscope, 100(10 Pt. 1), 1116-1121. Retrieved from https://www.ncbi.nlm.nih.gov/pubmed/2215046 
Leder, S. B., Pauloski, B. R., Rademaker, A. W., Grammer, T., Dikeman, K., Kazandjian, M., ... Logemann, J. A. (2013). Verbal communication for the ventilator-dependent patient requiring an inflated tracheotomy tube cuff: A prospective, multicenter study on the Blom tracheotomy tube with speech inner cannula. Head \& Neck, 35(4), 505-510. https://doi.org/10.1002/ hed. 22990

Manzano, J. L., Lubillo, S., Henriquez, D., Martin, J. C., Perez, M. C., \& Wilson, D. J. (1993). Verbal communication of ventilator-dependent patients. Critical Care Medicine, 21(4), 512-517. Retrieved from https://www-ncbi-nlm-nih-gov.proxy1. library.jhu.edu/pubmed/8472569

Maslow, A. H. (1943). A theory of human motivation. Psychological Review, 50(4), 370-396. https://doi.org/10.1037/h0054346

McGrath, B., Lynch, J., Wilson, M., Nicholson, L., \& Wallace, S. (2016). Above cuff vocalisation: A novel technique for communication in the ventilator-dependent tracheostomy patient. Journal of Intensive Care Society, 17(1), 19-26. https://doi.org/ 10.1177/1751143715607549

Merritt, R. M., Bent, J. P., \& Smith, R. J. (1997). Suprastomal granulation tissue and pediatric tracheotomy decannulation. The Laryngoscope, 107(7), 868-871.

Nakarada-Kordic, I., Patterson, N., Wrapson, J., \& Reay, S. D. (2018). A systematic review of patient and caregiver experiences with a tracheostomy. Patient, 11(2), 175-191. https://doi.org/ 10.1007/s40271-017-0277-1

Nomori, H. (2004). Tracheostomy tube enabling speech during mechanical ventilation. Chest, 125(3), 1046-1051. https://doi. org/10.1378/chest.125.3.1046

Pandian, V., Smith, C. P., Cole, T. K., Bhatti, N. I., Mirski, M. A., Yarmus, L. B., \& Feller-Kopman, D. J. (2014). Optimizing communication in mechanically ventilated patients. Journal of
Medical Speech-Language Pathology, 21(4), 309-318. Retrieved from https://www.ncbi.nlm.nih.gov/pmc/articles/PMC4242093/ pdf/nihms596365.pdf

Passy-Muir. (2003). Passy-Muir tracheostomy and ventilator speaking valve resource guide. Irvine, CA: Author.

Pryor, L. N., Ward, E. C., Cornwell, P. L., O'Connor, S. N., \& Chapman, M. J. (2016). Establishing phonation using the Blom ${ }^{\circledR}$ tracheostomy tube system: A report of three cases post cervical spinal cord injury. Speech, Language and Hearing, 19(4), 227-237. https://doi.org/10.1080/2050571X.2016. 1196035

Rehm, C. G., Wanek, S. M., Gagnon, E. B., Pearson, S. K., \& Mullins, R. J. (2002). Cricothyroidotomy for elective airway management in critically ill trauma patients with technically challenging neck anatomy. Critical Care, 6(6), 531-535.

Siddharth, P., \& Mazzarella, L. (1985). Granuloma associated with fenestrated tracheostomy tubes. American Journal of Surgery, 150(2), 279-280. https://doi.org/10.1016/0002-9610(85)90138-2

Sirgy, M. J. (1986). A quality of life therory derived from Maslow's developmental perspective. The American Journal of Economic and Sociology, 45(3), 329-342. https://doi.org/10.1111/j.15367150.1986.tb02394.x

Snyder, G. M. (1983). Individualized placement of tracheostomy tube fenestration and in-situ examinations with fiberoptic layngoscope. Respiratory Care, 28(10), 1294-1298.

Ward, E., Pandian, V., \& Brenner, M. J. (2018). The primacy of patient-centered outcomes in tracheostomy care. $\mathrm{Pa}$ tient, 11(2), 143-145. https://doi.org/10.1007/s40271-0170283-3

Wiegand, D. J., \& Carlson, K. K. (Eds.). (2010). AACN procedure manual for critical care (6th ed.). Philadelphia, PA: Elsevier Sauders. 